\title{
Integrating Health Literacy Questions into a Statewide Behavioral Risk Factor Surveillance System (BRFSS) Questionnaire
} Amy Chesser, Ph.D. ${ }^{1}$, Jared Reyes, M.Ed. ${ }^{1}$, Kyle Smothers, B.S. ${ }^{1}$, Nikki Keene Woods, Ph.D., M.P.H. ${ }^{2}$

${ }^{1}$ University of Kansas School of Medicine-Wichita

Department of Family and Community Medicine

${ }^{2}$ Wichita State University Department of Public Health Sciences

\begin{abstract}
Objectives. The purpose of this pilot study was to evaluate the feasibility of adding health literacy questions to a state health assessment questionnaire.

Methods. Researchers conducted a series of telephone interviews $(\mathrm{N}=20)$ to test the telephone administration of three health literacy screening questions with a convenience sample. Feedback obtained during the telephone interviews was used to revise the questions for clarity. The revised questions were proposed as an addition to the Kansas Behavioral Risk Factor Surveillance System (BRFSS).

Results. Pilot data included minor modifications to the language of the questions to broaden their interpretation outside of a hospital setting. Most participants $(90 \%, n=18)$ had adequate health literacy. The proposed questions were approved for addition to the BRFSS questionnaire. Prompts were added to a telephone script to aid BRFSS survey administrators.

Conclusion. As one of the first statewide health literacy assessments, this study has demonstrated one method for collecting baseline data. This new methodology has the potential to impact both patient care and broad public health efforts.

KS J Med 2014; 7(2):96-103.
\end{abstract}

\section{Introduction}

Low health literacy is associated with the inability to access available health information, ${ }^{1,2}$ decreased use of preventive health services, ${ }^{3,4}$ patients reporting more barriers to following health recommendations, ${ }^{5,6}$ decreased ability to reach treatment goals, ${ }^{7}$ and increased depression when dealing with chronic conditions. ${ }^{3,8}$ Low health literacy may contribute to the inappropriate use of healthcare services and increased healthcare spending. ${ }^{9,10}$

Recent data on the prevalence of limited literacy, as reported by the Centers for Disease Control and Prevention (CDC), ${ }^{11}$ come from the 2003 National Assessment of Adult Literacy (NAAL). In Kansas, an estimated $8 \%(n=164,000)$ of the population lack basic prose literacy skills. At the county level, this estimate ranges from $4 \%$ to $32 \% .^{12}$ Health literacy differs from prose literacy in that health literacy refers to "all the skills necessary to understand and communicate health information," including knowledge of the human body, health behaviors, and the healthcare system. ${ }^{11}$ Prose literacy is "the knowledge and skills needed to perform prose tasks" (i.e., to search, comprehend, and use information from continuous text including editorials, news stories, brochures, and instructional materials).

A statewide assessment of health literacy would provide key information to support large-scale coordinated interventions to improve health literacy. Tailored and targeted efforts to improve health literacy have been successful with individuals and populations, respectively. ${ }^{13,14}$ Therefore, 
identifying a feasible method for reaching the long-term goal of assessing health literacy at the state level was important. The primary objective of this study was to evaluate the feasibility of using a brief screening tool to assess population health literacy using the Behavioral Risk Factor Surveillance System (BRFSS).

\section{Methods}

Health screening questionnaire. The Behavioral Risk Factor Surveillance System is a state-based, randomized digit dialing, telephone survey coordinated annually by the CDC. ${ }^{15,16}$ BRFSS field operations, however, are managed by state health departments to collect self-reported information including health risk behaviors, clinical preventive health practices, and healthcare access that are associated with the leading causes of morbidity and mortality in the US. State survey data are transmitted to the CDC for editing, processing, weighting, and analysis, then returned to the state health departments for their own use. ${ }^{17}$

In Kansas, the BRFSS questions include core questions asked by every state, optional modules, and state-added questions. The core question topics include health status, health care access, healthy days, life satisfaction, emotional satisfaction, disability, tobacco use, alcohol use, exercise, immunization, HIV/AIDS, diabetes, asthma, and cardiovascular disease. Additional questions regarding topics such as hypertension awareness and men and women's health are alternated within the BRFSS from year to year. Optional question modules include questions about different topics that can vary from state to state. State-added questions are added based on the public health needs of the state, though they are not the responsibility of CDC for analysis. ${ }^{16}$ Using response data from the BRFSS 2012, sample sizes for the health literacy questions could be 10,000 respondents with a target of
8,000 from landline and 2,000 from cellular phones (20\% of the state's total landline and cell phone sample). ${ }^{16}$

Health literacy screening tool. The most feasible health literacy screening tool to implement into the BRFSS was a validated three question health literacy tool. The three question tool was validated for use in both inpatient and outpatient settings. ${ }^{18,19}$ Questions for the screening tool are based on six themes which emerged from a qualitative study, including navigation, completing forms, provider-patient interactions, following medication instructions, appointment slips, and coping strategies. ${ }^{20,21}$ Questions were designed to assess problems with understanding written medical information, such as "How often do you have someone help you read hospital materials?" and "How often do you have problems learning about your medical condition because of difficulty understanding written information?" Both questions are scored using a 5-point Likert scale ranging from 1 $=$ "Always" to $5=$ "Never." One question was designed to assess patient comfort with filling out medical forms by asking, "How confident are you filling out forms by yourself?" This question is scored using a 5point Likert scale ranging from $1=$ "Not at all" to 5 = "Extremely".

For the purposes of this study, risk for low health literacy was determined by a calculation from a cumulative score. Respondents with scores of 3-8 indicated low health literacy; scores of 9-14 indicated moderate health literacy; and a score of 15 indicated high health literacy.

Procedure. In October 2011, research staff from the Department of Family and Community Medicine (DFCM) at the University of Kansas School of MedicineWichita (KUSM-W) conducted a series of telephone interviews $(\mathrm{N}=20)$ with a convenience sample to test the administration of an amended version of the three 
question health literacy screening tool. ${ }^{21}$ The interviews were standardized, including a protocol and script. The script was piloted with a sample of two. The convenience sample was accessed through acquaintances of the interviewers which included access to their telephone numbers. The proposed questions were not asked in previous BRFSS, either nationally or by the state of Kansas. The three question screening tool was used regionally by the authors as a component of previous research conduction in Saline and Sedgwick counties. ${ }^{22,23}$

Four investigators (two research associates and two Ph.D. social science researchers) contacted individuals in the state of Kansas via telephone and conducted independent telephone interviews. Phone calls to participants were made during the work day and evenings over one week. Notes of each call were logged and documents were issued to the principal investigator for qualitative feedback.

Participants were told they would be asked three questions to assess health literacy skills. Each respondent was asked one of the three questions and encouraged through a series of short prompts to assess their understanding of the question. Respondents also were asked what they would add or modify for each question to ensure clarity.

At the completion of the pilot study, modifications to the language in the original questions were made when necessary. Results were presented to the Kansas Department of Health and Environment (KDHE) for approval and addition to the 2012 BRFSS questionnaire. The KDHE adopted the pilot study recommendations and used the suggestions with additional prompts for the addition of health literacy questions to the 2012 BRFSS questionnaire.

The study was approved by the KDHE Institutional Review Board and received approval for future data analysis from the University of Kansas School of MedicineWichita Institutional Review Board.

\section{Results}

The principal investigator presented the proposed addition of the health literacy questions to the optional/state-added module during the Kansas BRFSS Annual Planning Meeting in August 2011. The board accepted the addition of the health literacy questions and notified the study team (see Figure 1). Table 1 displays the demographic information of participants. In general, participants were mostly female, well educated, and employed in wage-earning occupations.

Question 1 was: "How often do you have someone help you read hospital materials?” Responses for Question 1 indicated the majority "never" $(40 \% ; n=8)$ or "rarely" $(40 \% ; n=8)$ needed help reading hospital materials. Results showed four "sometimes" (20\%) responses and only one (5\%) "often” response.

Question 2 was: "How often do you have problems learning about your medical condition because of difficulty understanding written information?” Responses for Question 2 showed three respondents were unclear of the term "medical condition”. Several participants also asked to have this question repeated. The investigators recommended changing the word "medical" to "health" condition. The majority of respondents indicated "never" $(30 \% ; n=6)$ or "rarely" $(45 \% ; n=9)$ followed by "sometimes" (20\%; $n=4)$ and "often" (5\%; $n=1)$.

Responses for Question 3, "How confident are you in filling out medical forms by yourself?”, indicated less than half of the sample had inquiries for the survey administrator. However, three participant inquiries were aimed at which "medical 


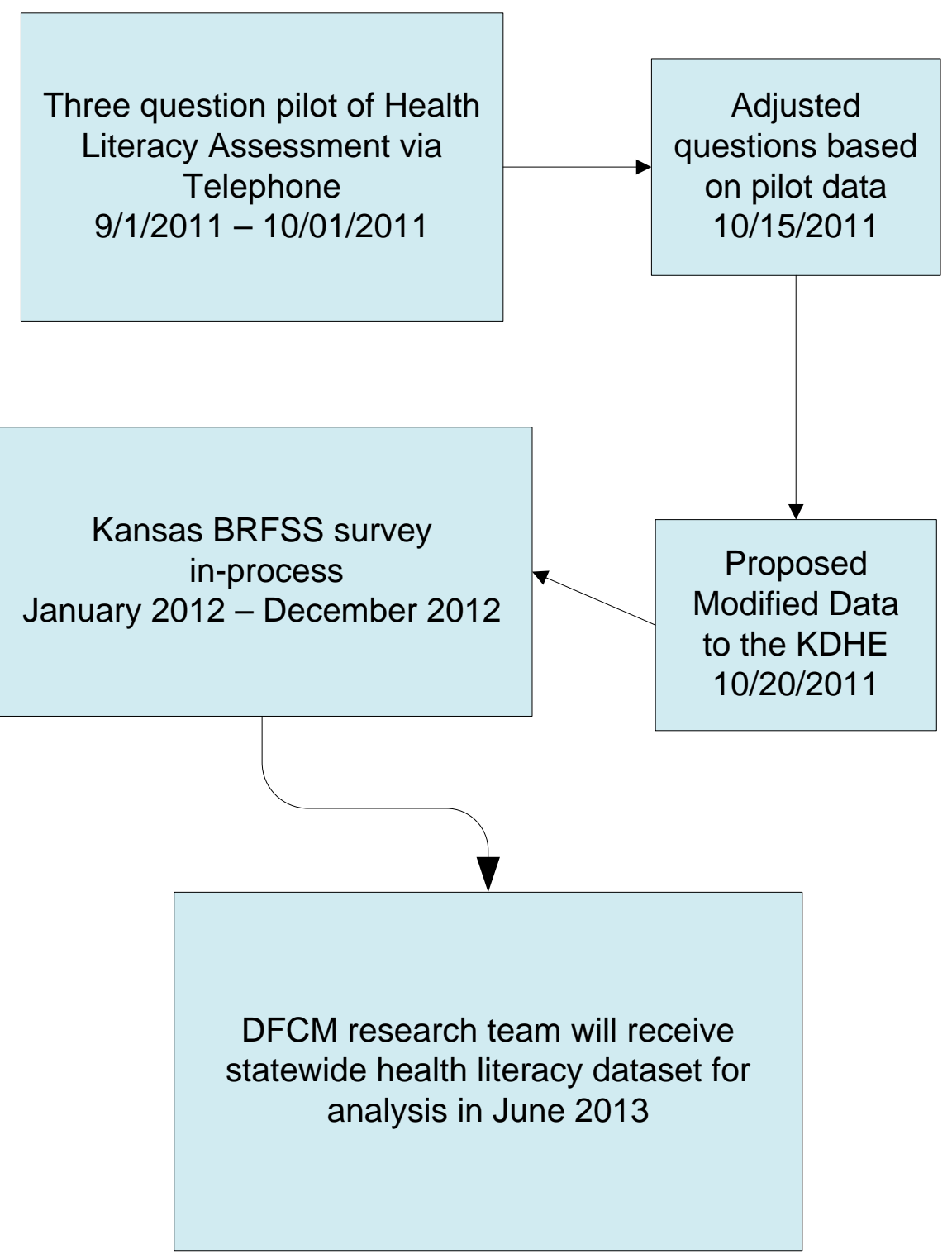

Figure 1. Kansas health literacy assessment development timeline.

forms" were referred to by this question. The research team recommended the addition of examples to describe "medical forms" such as: insurance forms, questionnaires, and doctors' office forms. For Question 3, 40\% (n = 8) responded "extremely"; 35\% $(\mathrm{n}=7)$ responded "quite a bit'; $20 \%(\mathrm{n}=4)$ responded "somewhat"; and $5 \%(\mathrm{n}=1)$ indicated "a little".

Overall, participants had little trouble understanding questions or choosing from the multiple choice selection of words. Some questions were understood easily with no flaws in structure or content. Pilot subjects with questions were able to respond appropriately to each of the three questions following clarification by the study team member or repetition of the question. Amended questions that were added to the 2012 BRFSS for the state of Kansas are in Table 2.

\section{Discussion}

Pilot testing of a three question health literacy screening tool, modification of questions, and addition of modified question 
Table 1. Participant demographics $(\mathrm{N}=20)$.

\begin{tabular}{|c|c|}
\hline \multicolumn{2}{|l|}{ Gender } \\
\hline Male & $6(30 \%)$ \\
Female & $14(70 \%)$ \\
\hline Age & $5(25 \%)$ \\
$18-25$ & $6(30 \%)$ \\
$26-35$ & $1(5 \%)$ \\
$36-45$ & $8(40 \%)$ \\
$46+$ & $20(100 \%)$ \\
\hline Race/Ethnicity \\
\hline Caucasian & $7(37 \%)$ \\
\hline Marital Status & $4(21 \%)$ \\
\hline Married & $1(5 \%)$ \\
Divorced & $7(37 \%)$ \\
\hline Widowed & $1(5 \%)$ \\
Never Married & $4(20 \%)$ \\
\hline Education Level & $5(25 \%)$ \\
\hline Some high school & $10(50 \%)$ \\
\hline Grade 12 or GED & $15(75 \%)$ \\
College 1-3 years & $1(5 \%)$ \\
College Graduate & $1(5 \%)$ \\
\hline Employment Status & $1(5 \%)$ \\
\hline Employed for wages & $2(10 \%)$ \\
\hline Self-employed & $18(90 \%)$ \\
\hline Homemaker & $2(10 \%)$ \\
\hline Student
\end{tabular}

Table 2. Amended three question health literacy assessment.

\begin{tabular}{|l|l|}
\cline { 2 - 3 } Question 1 & $\begin{array}{l}\text { How often do you have someone help you read medical materials? For } \\
\text { example: family member, friend, caregiver, doctor, nurse, or other health } \\
\text { professional. }\end{array}$ \\
Possible Answers & $\square$ Always $\square$ Often $\square$ Sometimes $\square$ Rarely $\square$ Never \\
Question 2 & $\begin{array}{l}\text { How often do you have problems learning about your health condition } \\
\text { because of difficulty in understanding written information? }\end{array}$ \\
Possible Answers & $\square$ Always $\square$ Often $\square$ Sometimes $\square$ Rarely $\square$ Never \\
Question 3 & $\begin{array}{l}\text { How confident are you in filling out medical forms by yourself? For } \\
\text { example insurance forms, questionnaires, and doctor's office forms. }\end{array}$ \\
\hline Possible Answers & $\square$ Not at all $\square$ A little $\square$ Somewhat $\square$ Quite a bit $\square$ Extremely \\
\hline
\end{tabular}


to the Kansas BRFSS statewide health assessment were essential first steps toward meeting our long-term objective of a statewide health literacy assessment. Data from the 2012 Kansas BRFSS survey will be analyzed by DFCM research staff and results will be disseminated. Results at the population-level will be reported to KDHE and key stakeholders for research purposes and program planning and implementation. Key stakeholders include public health entities, researchers, clinical providers, and healthcare professionals. The addition of a health literacy screening tool to a large health assessment survey may set a precedent for other states to emulate or modify to conduct similar population-level assessments.

While this study provides a novel approach for assessing health literacy across the state of Kansas, it is not without limitations. The sample size used to pilot the screening questions was small and not demographically representative of the Kansas population. The possibility exists that modifications to the three health literacy screening questions were not substantial enough to clarify the meaning of each question to demographics not represented in our sample. Thus, it is possible that some selection bias may have influenced the clarification of questions. Health literacy levels of each participant may have influenced the clarifications that were needed to understand each question. Even with these limitations, the overall impact of the study is not diminished.

To our knowledge, this is the first time these questions have been piloted for a telephone issued, statewide survey. The addition of the three question health literacy screening tool to an already existing statewide health assessment survey may be a feasible and inexpensive option for assessing health literacy in the state of Kansas and building collaboration between university researchers, academic faculty, federal, state, and local governments. Since the tool can be administered over the phone in a short period of time, the cost for administering this tool in a large population study may be significantly less than with another health literacy assessment tool.

The addition of questions to the 2012 BRFSS required collaboration between the CDC, KDHE, local health departments, and public health professionals. A key strength of this study is that it facilitated a first step in collaboration between these agencies for addressing health literacy in Kansas, and working toward goals set out in the CDC's National Action Plan to Improve Health Literacy. ${ }^{11}$

\section{Conclusions}

Addressing health literacy requires engagement from multiple healthcare sectors. University and state-run agencies should continue to collaborate to support the assessment of health literacy levels. Both public health and medicine may benefit from exploring health literacy rates using the BRFSS questionnaire.

Future research should focus on identifying risk factors associated with low health literacy and developing targeted interventions for improving health literacy in areas marked by low health literacy. Future studies should utilize the populationlevel health literacy data in Kansas to analyze trends and identify individuals with the highest risk for poor health outcomes. These data provide the opportunity for scientists and practitioners alike in Kansas to be the health literacy research pioneers. 


\section{References}

${ }^{1}$ Quinn CC, Clough SS, Minor JM, Lender D, Okafor MC, Gruber-Baldini A. WellDoc mobile diabetes management randomized controlled trial: Change in clinical and behavioral outcomes and patient and physician satisfaction. Diabetes Technol Ther 2008; 10(3):160168. PMID: 18473689.

2 Pleasant A, McKinney J. Coming to consensus on health literacy measurement: An online discussion and consensus-gauging process. Nurs Outlook 2011; 59(2):95106. PMID: 21402205.

3 Berkman ND, Dewalt DA, Pignone MP, et al. Literacy and health outcomes. Evid Rep Technol Assess (Summ) 2004; (87):18. PMID: 15819598.

${ }^{4}$ Kripalani S, Sharma J, Justice E, et al. Low-literacy interventions to promote discussion of prostate cancer: A randomized controlled trial. Am J Prev Med 2007; 33(2):83-90. PMID: 17673094.

${ }^{5}$ Peterson NB, Dwyer KA, Mulvaney SA, Dietrich MS, Rothman RL. The influence of health literacy on colorectal cancer screening knowledge, beliefs and behavior. J Natl Med Assoc 2007; 99(10):1105-1112. PMID: 17987913.

${ }^{6}$ Shieh C, Mays R, McDaniel A, Yu J. Health literacy and its association with the use of information sources and with barriers to information seeking in clinicbased pregnant women. Health Care Women Int 2009; 30(11):971-988. PMID: 19809901.

7 Rothman RL, DeWalt DA, Malone R, et al. Influence of patient literacy on the effectiveness of a primary care-based diabetes disease management program. JAMA 2004; 292(14):1711-1716. PMID: 15479936.

8 Nielsen-Bohlman L, Panzer AM, Kindig DA. (Editors). Health Literacy: A Prescription to End Confusion.
Washington, D.C.: National Academies Press, 2004.

${ }^{9}$ Hardie NA, Kyanko K, Busch S, Losasso AT, Levin RA. Health literacy and health care spending and utilization in a consumer-driven health plan. J Health Commun 2011; 16(Suppl 3):308-321. PMID: 21951260.

${ }^{10}$ Sudore RL, Mehta KM, Simonsick EM, et al. Limited literacy in older people and disparities in health and healthcare access. J Am Geriatr Soc 2006; 54(5):770-776. PMID: 16696742.

${ }^{11}$ US Department of Health and Human Services, Office of Disease Prevention and Health Promotion. National Action Plan to Improve Health Literacy. Washington, D.C.: US Department of Health and Human Services, 2010.

${ }^{12}$ Mohadjer L, Kalton G, Krenzke T, et al. National Assessment of Adult Literacy: Indirect county and state estimates of the percentage of adults at the lowest literacy level for 1992 and 2003. Washington, D.C.: US Department of Education National Center for Education Statistics, January 2009.

${ }^{13}$ Giuse NB, Koonce TY, Storrow AB, Kusnoor SV, Ye F. Using health literacy and learning style preferences to optimize the delivery of health information. $\mathrm{J}$ Health Commun 2012; 17(Suppl 3):122140. PMID: 23030566.

${ }^{14}$ Rosal MC, Ockene IS, Restrepo A, et al. Randomized trial of a literacy-sensitive, culturally tailored diabetes selfmanagement intervention for low-income latinos: Latinos en control. Diabetes Care 2011; 34(4):838-844. PMID: 21378213.

${ }^{15}$ Pierannunzi C, Hu SS, Balluz L. A systematic review of publications assessing reliability and validity of the Behavioral Risk Factor Surveillance System (BRFSS), 2004-2011. BMC Med 
Res Methodol 2013; 13:49. PMID: 23522349.

${ }^{16}$ US Centers for Disease Control and Prevention. Behavior Risk Factor Surveillance System. December 23, 2013. Available at: http://www.cdc.gov/brfss.

${ }^{17}$ Mokdad AH. The Behavioral Risk Factors Surveillance System: Past, present, and future. Annu Rev Public Health 2009; 30:43-54. PMID: 19705555.

${ }^{18}$ Chew LD, Griffin JM, Partin MR, et al. Validation of screening questions for limited health literacy in a large VA outpatient population. J Gen Intern Med 2008; 23(5):561-566. PMID: 18335281.

${ }^{19}$ Sarkar U, Schillinger D, López A, Sudore R. Validation of self-reported health literacy questions among diverse English and Spanish-speaking populations. J Gen Intern Med 2011; 26(3):265-271. PMID: 21057882.
${ }^{20}$ Baker DW, Parker RM, Williams MV, et al. The health care experience of patients with low literacy. Arch Fam Med 1996; 5(6):329-334. PMID: 8640322.

${ }^{21}$ Chew LD, Bradley KA, Boyko EJ. Brief questions to identify patients with inadequate health literacy. Fam Med 2004; 36(8):588-594. PMID: 15343421.

${ }^{22}$ Chesser A, Reyes J, Woods NK, Williams K, Kraft R. Reliability in patient-centered observations of family physicians. Fam Med 2013; 45(6):428-432. PMID: 23743944.

${ }^{23}$ Woods NK, Chesser AK, Wipperman J. Describing adolescent breastfeeding environments through focus groups in an urban community. J Prim Care Community Health. 2013; 4(4):307-310. PMID: 23799673.

Keywords: health literacy, behavioral risk factor surveillance system 